\title{
SUPLEMENTAÇÃO ASSOCIADA COM LASALOCIDA PARA NOVILHOS EM TERMINAÇÃO EM PASTAGEM CULTIVADA DE INVERNO.
}

\section{SUPPLEMENTATION ASSOCIATED WITH LASALOCID FOR FINISHING BEEF STEERS ON CULTIVATED WINTER PASTURE.}

\author{
João Restle ${ }^{1}$, André Brugnara Soares ${ }^{2}$, Marcus Vinícius Back Ferreira ${ }^{3}$, \\ Ivan Luiz Brondani ${ }^{4}$, Katia Gobatti Calça ${ }^{5}$.
}

RESUMO

O experimento teve como objetivo avaliar o ganho de peso na fase de terminação de novilhos de corte com peso médio inicial de $357 \pm 15 \mathrm{~kg}$ e idade média de 24 meses, suplementados em pastagem de aveia preta + azevém, com um resíduo médio de 2356kg MS/ha, 14,84\% de PB e uma DIVMO de 56,31\%. Foram utilizados dois níveis de suplementação, correspondendo a 0,5 ou $1,0 \%$ do peso vivo, associado ou não à lasalocida sódica. $O$ concentrado utilizado para suplementação foi milho triturado. Nos tratamentos que incluíam lasalocida, esta foi misturada numa proporção que permitisse um consumo de 225 mg/animal/dia de lasalocida. $O$ desenho experimental foi inteiramente casualizado com arranjo fatorial de $2 \times 2$. Não houve interação significativa para ganho de peso médio diário (GMD) entre o nível de suplementação e o uso da lasalocida. O GMD foi de 1,502 $\pm 0,07$ e 1,532 $\pm 0,07 \mathrm{~kg} /$ dia para os níveis 0,5 e $1 \%$ do peso vivo de suplementação e de 1,457 $\pm 0,07$ e 1,577 $\pm 0,07 \mathrm{~kg} / \mathrm{dia}$ com e sem lasalocida, respectivamente. Os resultados obtidos mostram que, em termos de ganho de peso médio diário, não há vantagem em elevar o nível de suplementação de 0,5 para $1 \%$ do peso vivo, indicando também que nesta faixa de suplementação ocorre apenas um efeito substitutivo do suplemento.

Palavras-chave: aveia preta, azevém, ionóforo, milho, pastejo, ganho de peso.

\section{SUMMARY}

The experiment evaluated the weight gain during the finishing period of 24 months old beef steers, with an average initial weight of $365 \mathrm{~kg}$, supplemented on oats plus ryegrass pasture, with a residue of $2356 \mathrm{~kg} \mathrm{DM} / \mathrm{ha}, 14.84 \% \mathrm{CP}$ and a IVOMD of $56.31 \%$. Two levels of supplementation, corresponding to 0.5 or $1 \%$ of the live weight, associated or not with lasalocid, were used. The concentrate used for supplementation was ground corn. The treatments that included lasalocid, it was mixed to the corn in a proportion that allowed a consumption of $225 \mathrm{mg}$ per animal per day. The experimental design used was the completely randomized, in a $2 \times 2$ factorial scheme. No significant interaction, for average daily weight gain, was observed between the supplementation level and the use of lasalocid. Average daily weight gain was 1.501 and $1.532 \mathrm{~kg} /$ day for the .5 and $1 \%$ supplementation level, respectively, and 1.456 and $1.577 \mathrm{~kg} /$ day for the inclusion or not of lasalocid. The results showed that in terms of daily weight gain, there is no advantage of increasing the supplementation level from .5 to $1 \%$, indicating also that in this range of supplementation only a substitutive effect occurs.

Key words: oats, ryegrass, ionophor, corn, grazing, weight gain.

\section{INTRODUÇÃO}

A utilização de pastagens anuais de inverno no sul do país, quando manejadas e fertilizadas adequadamente, tem resultado em elevados ganhos de peso por animal e por ha (RESTLE $\boldsymbol{e t}$ al., 1993, RESTLE $\boldsymbol{e t}$ al., 1998). No entanto, devido aos altos custos dessas pastagens (RESTLE $\boldsymbol{e t}$ al., 1998) devem-se buscar formas de utilizá-las de uma maneira mais eficiente.

Forrageiras como a aveia preta e o azevém apresentam, na fase de crescimento vegetativo, elevados níveis de proteína bruta (LUPATINI et al., 1997), bem superiores aos valores preconizados pelo NRC (1996) para proporcionar elevados ganhos de

\footnotetext{
${ }^{1}$ Engenheiro Agrônomo, PhD., Professor Titular, Bolsista do CNPq, Departamento de Zootecnia da UFSM, $97105-900$ Santa Maria, RS. Autor para correspondência. E-mail: jorestle@ccr.ufsm.br

${ }^{2}$ Engenheiro Agrônomo, Mestrando em Zootecnia, UFSM, Departamento de Zootecnia da UFSM.

${ }^{3}$ Aluno do curso de Medicina Veterinária, Bolsista de iniciação cientifica CNPq.

${ }^{4}$ Zootecnista, MSc., Professor Assistente do Departamento de Zootecnia da UFSM.

${ }^{5}$ Aluna do curso de Zootecnia - UFSM. 
peso. Desta maneira ocorre um desperdício de proteína bruta no sistema, lembrando que se trata de um dos nutrientes de maior valor comercial. Por outro lado, essas forrageiras apresentam, na fase de crescimento vegetativo, elevado conteúdo de água o que pode limitar o consumo de matéria seca por parte do animal devido à limitação física do rúmen. Nesta situação, o consumo de energia poderá ser insuficiente para atender o potencial máximo de ganho de peso, principalmente para animais na fase de terminação.

A suplementação com um concentrado energético para animais mantidos em pastagem de inverno permite um melhor balanceamento de nutrientes na dieta do animal, podendo resultar um efeito aditivo. No entanto, segundo PASCOAL \& RESTLE (1996), a suplementação em pastagens com alta digestibilidade, resulta basicamente em efeito substitutivo, resultando em aumento na carga animal/ha. Dentre as práticas de alimentação mais intensivas, a suplementação é a mais fácil de ser adotada pelo produtor, pois o custo de implantação é reduzido, necessitando somente de cochos que podem ser confeccionados na propriedade. Em anos em que o preço do grão é atrativo, essa técnica pode ser usada em larga escala (PASCOAL \& RESTLE, 1996).

O uso de ionóforos tem resultado em benefícios na produção de bovinos de corte (THOMAS, 1998). A lasalocida sódica é um ionóforo que tem ação sobre a população microbiana do rúmen, alterando as proporções finais de ácidos graxos voláteis, principalmente pelo aumento na proporção de ácido propiônico e diminuição do ácido acético e butírico (THONNEY et al., 1981). Esta alteração é benéfica, pois o ácido propiônico é energicamente mais eficiente, além de reduzir as perdas de metano associadas à produção de ácido acético e butírico. A utilização de ionóforos como monensina e lasalocida na dieta de animais confinados tem resultado, principalmente, em melhor eficiência alimentar, além de favorecer o ganho de peso. No entanto, o uso de ionóforos fornecidos via suplemento para animais em pastagem tem apresentado resultados variados. OLIVER (1975), suplementando animais em pastagem de capim bermuda, obteve ganhos diários superiores quando os animais recebiam lasalocida no suplemento. Resultados semelhantes são relatados por POTTER et al. (1976) ao suplementar monensina para animais mantidos em pastagem cultivada. No entanto, UTLEY et al. (1978) e, mais recentemente, RESTLE et al. (1997) suplementando respectivamente, monensina e lasalocida para animais mantidos em pastagem, não verificaram efeito positivo no ganho de peso. No entanto, em ambos os trabalhos a adição de ionóforos resultou em melhor eficiência de utilização da pastagem.

O presente trabalho teve como objetivo estudar os efeitos de diferentes níveis de suplementação com milho triturado, associado ou não à lasalocida, no ganho de peso de novilhos de corte na fase de terminação, mantidos em pastagem cultivada de inverno.

\section{MATERIAL E MÉTODOS}

O experimento foi conduzido no período de 05/09/95 a 10/11/95 sobre solo Podzólico vermelhoamarelo, no Departamento de Zootecnia da Universidade Federal de Santa Maria, situada na Depressão Central do Rio Grande do Sul, numa altitude de $95 \mathrm{~m}$, latitude $29^{\circ} 43^{\prime}$ sul e longitude $53^{\circ} 42^{\prime}$ oeste. O clima da região é o cfa (subtropical úmido), conforme a classificação Köppen (MORENO, 1961).

Foram avaliados dois níveis de suplementação para novilhos na fase de terminação, em quantidades equivalentes a 0,5 e $1,0 \%$ do peso vivo (PV) associados ou não à lasalocida sódica. Os tratamentos estudados foram níveis de suplementação de 0,5 e $1 \%$ do peso vivo, com a inclusão ou não de lasalocida.

Foram utilizados 32 novilhos cruzas charolês x nelore, com peso médio inicial de $357 \pm 15 \mathrm{~kg}$ e idade média de 24 meses. Cada tratamento foi composto por 8 animais. A carga animal média usada foi de $1450 \mathrm{~kg}$ de $\mathrm{PV} / \mathrm{ha}$, sendo que os animais foram mantidos na mesma área de 9 ha de pastagem cultivada de inverno formada por aveia preta (Avena strigosa) e azevém (Lolium multiflorum). A implantação da pastagem foi realizada em março e utilizada a partir de maio com outras categorias de animais, sendo que, ao iniciar o presente experimento, predominava o azevém já que a aveia preta estava finalizando o seu ciclo vegetativo.

O sistema de pastejo empregado foi o contínuo com lotação fixa. O resíduo médio encontrado ficou acima de $2000 \mathrm{~kg}$ de MS/ha, para tal realizaram-se avaliações a cada 21 dias, através de corte de 25 amostras escolhidas ao acaso na área. Por ocasião das avaliações, eram retiradas duas amostras compostas, sendo uma para realizar a separação botânica e outra para determinação das porcentagens de matéria seca (MS), proteína bruta (PB), digestibilidade in vitro da matéria orgânica (DIVMO) e fibra em detergente neutro (FDN).

O concentrado utilizado para suplementação foi milho triturado. A este foi agregado uma quantidade de sal, visando a fornecer $25 \mathrm{~g} / \mathrm{animal} /$ 
dia. Nos tratamentos que incluíam ionóforo foram adicionados ao milho moído uma quantidade determinada visando a fornecer uma quantidade de lasalocida sódica de $225 \mathrm{mg}$ /animal/dia.

Como todos os animais vinham sendo suplementados com concentrado em campo nativo, no período que antecedeu o início do experimento, os mesmos não sofreram adaptação gradativa do suplemento. Os novilhos eram mantidos na mesma área e, diariamente, pela manhã eram separados nos seus respectivos tratamentos para o fornecimento do suplemento em cochos com acesso de $1 \mathrm{~m}$ linear por animal. Os animais permaneciam nos piquetes de alimentação até consumirem totalmente a ração, o que durava 2 horas, após eram soltos novamente na pastagem.

As pesagens, precedidas de um jejum de 12 horas, foram feitas no início e final do período experimental, com pesagens intermediárias a cada 21 dias. Nos dias de pesagem, a suplementação só ocorria após os animais terem pastejados no mínimo 3 horas, este manejo visava a prevenir algum distúrbio gastrointestinal devido à alta quantidade de concentrado após um jejum prolongado.

O delineamento experimental foi inteiramente casualizado em esquema fatorial 2x2 (2 níveis de suplementação e a inclusão ou não de lasalocida), com oito repetições. Os dados foram submetidos à análise de variância (SAS, 1990), através do teste $\mathrm{F}$ a 5\% de significância, sendo usado o seguinte modelo matemático: $\mathrm{Y}_{\mathrm{ikj}}=\mathrm{M}+\mathrm{T}_{\mathrm{i}}+\mathrm{T}_{\mathrm{k}}+\mathrm{T}_{\mathrm{i}} \mathrm{P}_{\mathrm{k}}+\mathrm{E}_{\mathrm{ikj}}$, onde cada variável dependente está em função da média de todas as observações (M), efeito do nível de suplementação $\left(\mathrm{T}_{\mathrm{i}}\right)$, efeito da inclusão de lasalocida $\left(T_{k}\right)$, efeito da interação entre nível de suplementação e inclusão de lasalocida $\left(\mathrm{T}_{\mathrm{i}} * \mathrm{P}_{\mathrm{k}}\right)$ e efeito do erro aleatório $\left(\mathrm{E}_{\mathrm{ikj}}\right)$.

\section{RESULTADOS E DISCUSSÃO}

O resíduo médio da pastagem foi de 2356kg MS/ha, próximo ao que MORAES (1991) determinou como ideal para maximização do ganho médio diário. A composição botânica da pastagem apresentou na matéria seca disponível, 59,05\% de azevém, $13,10 \%$ de outras gramíneas e $24,37 \%$ de material morto. Verifica-se que o azevém contribuiu com $59,05 \%$ da forragem disponível para os novilhos. O material morto era constituído principalmente de aveia preta que já havia completado seu ciclo. Cabe ressaltar que a pastagem havia sido primeiramente utilizada, a partir de maio, com outras categorias animais.

Com relação à qualidade da pastagem foi verificado que a amostra composta apresentou
14,84\% de PB, 68,90\% de FDN e uma DIVMO de $56,31 \%$. Já o azevém apresentou $15,54 \%$ de PB, $62,50 \%$ de FDN e uma DIVMO de 67,97\%. Observou-se que, tanto na fração azevém como na amostra composta, o nível de PB foi elevado, não sendo um fator limitante para o ganho de peso dos novilhos (NRC, 1996). Nota-se também que a DIVMO foi elevada, principalmente no azevém que representou a maior fração da matéria seca disponível. Como o resíduo médio da pastagem foi elevado, permitindo a seleção do material pastejado, a qualidade da forragem consumida pelos animais deve ter sido superior inclusive à do azevém amostrado para análise laboratorial, já que este é cortado rente ao solo. O milho, que apresentou $85 \%$ de MS, $10,03 \%$ de PB e $97,77 \%$ de DIVMO, foi basicamente um complemento energético da dieta.

A análise de variância não mostrou interação significativa $(\mathrm{P}>0,05)$ entre o nível de suplementação e o uso ou não de lasalocida para ganho de peso médio diário; desta forma, os dados serão apresentados e discutidos separadamente para os efeitos principais. O ganho de peso médio diário (GMD) que foi de 1,502 $\pm 0,07$ e 1,532 $\pm 0,07 \mathrm{~kg} / \mathrm{animal} / \mathrm{dia}$ para os níveis 0,5 e $1,0 \%$ de suplementação, respectivamente, não apresentaram diferença significativa $(\mathrm{P}>0,05)$ (tabela 1). Estes dados são levemente inferiores aos encontrados por RESTLE $\boldsymbol{e t}$ al. (1998), que obtiveram um GMD de $1,598 \mathrm{~kg}$, neste mesmo período, usando a mesma categoria animal em condições semelhantes de pastagem, no entanto, sem suplementação. Isto indica que nestas condições de pastagem com alta qualidade, não existe grande diferença no GMD quando os animais são suplementados ou não, já que o efeito da suplementação é basicamente substitutivo. Já EIFERT et al. (1997) verificaram resposta da suplementação no GMD. Os autores trabalharam, também, com novilhos de sobreano, recebendo diferentes níveis de suplementação, porém com sorgo moído, em pastejo horário

Tabela 1 - Peso inicial, peso final e ganho de peso médio diário (GMD) de acordo com o nível de suplementação e inclusão ou não de lasalocida sódica..

\begin{tabular}{cccc}
\hline TRATAMENTOS & Peso inicial & Peso final & $\begin{array}{c}\text { GMD } \\
(\mathrm{kg} / \mathrm{dia})\end{array}$ \\
\hline & \multicolumn{3}{c}{ nível de suplementação } \\
\cline { 2 - 4 } 0,5\% de suplementação & 356 & 456 & 1,501 \\
$1,0 \%$ de suplementação & 358 & 458 & 1,532 \\
\hline \multicolumn{4}{c}{ inclusão de lasalocida } \\
com lasalocida & 356 & 453 & 1,456 \\
sem lasalocida & 358 & 461 & 1,577 \\
& \multicolumn{3}{c}{} \\
\hline
\end{tabular}


(duas horas de manhã e duas de tarde) em pastagem de triticale + azevém, que apresentou um resíduo médio de $1100 \mathrm{~kg}$ MS/ha. Os GMD obtidos foram de 1,$176 ; 1,397 ; 1,395$ e 1,332 para os níveis de 0,25 , 35 e $45 \%$ do consumo estimado sob a forma de suplemento. Observou-se que a suplementação favoreceu o ganho de peso dos novilhos, no entanto, não houve diferença no ganho de peso para os diferentes níveis de suplementação, o que confirma a constatação do presente experimento, de que em pastagem de alta qualidade ocorre um efeito substitutivo da forragem pelo concentrado, sem alterar o ganho de peso dos animais.

O efeito da substituição do consumo de forragem pelo concentrado também foi relatado por RISSO et al. (1991); MATTOS et al. (1992) e RESTLE et al. (1996), sendo que os últimos também trabalharam com níveis de 0,5 e $1,0 \%$ do PV de concentrado sobre campo nativo melhorado. De acordo com Lange, apud MIERES (1997), os efeitos do suplemento alimentar no consumo de matéria seca podem ser aditivos, substitutivos, aditivos/substitutivos, aditivos com estímulos ou substitutivo com redução. O efeito aditivo ocorre geralmente quando o consumo de nutrientes via forragem é reduzido, por motivo de baixa qualidade, pouco tempo de pastejo, etc. Este efeito aumenta o ganho de peso médio diário (GMD) dos animais. Por outro lado, quando a forragem apresenta-se com boa qualidade, como no presente experimento, ocorre o efeito substitutivo, em que parte do consumo da forragem é trocado pelo consumo de suplemento. Este efeito, embora não aumente o GMD resulta em aumento da carga animal/ha pelo menor consumo da forragem, com isto o ganho de peso vivo/ha também será aumentado. No presente experimento, o ganho de peso/ha para os dois níveis de suplementação não teve condições de ser medido separadamente já que os animais permaneciam na mesma área. Outro aspecto que deve ser considerado ao analisar a não diferença no GMD entre os dois níveis de suplementação é que, mesmo com maior aporte energético no tratamento de $1 \%$ de suplemento, este nível pode ter afetado a digestão da fibra e diminuído a eficiência de utilização do material consumido da pastagem. Este fato foi verificado por DAVIES et al. (1997), utilizando os mesmos níveis de suplementação do presente experimento com a mesma categoria animal em pastagem de aveia preta.

Em relação ao uso do lasalocida (tabela 1), não foi encontrada diferença significativa $(\mathrm{P}>0,05)$ no GMD que foi de $1,457 \pm 0,07$ e 1,577 $\pm 0,07$ $\mathrm{kg} / \mathrm{animal} /$ dia, usando ou não lasalocida na dieta, respectivamente. Esta constatação confirma os resultados obtidos por RESTLE et al. (1997), que também usaram lasalocida sódica em pastagens cultivadas de inverno, porém suplementadas via sal comum, num consumo estimado de $250 \mathrm{mg}$ de lasalocida sódica/animal/dia, sendo que, neste trabalho, a categoria animal usada foi terneiras desmamadas. Convém salientar que no trabalho dos referidos autores foi verificado um ganho de peso vivo/ha $8,5 \%$ superior no tratamento que recebeu lasalocida sódica. Este incremento foi motivado pelo aumento em $7 \%$ da carga animal, indicando que neste tratamento houve menor consumo de matéria seca o que permitiu um aumento na capacidade de suporte da pastagem. Menores consumos de matéria seca, por animais que receberam ionóforos na dieta foram constatados em vários trabalhos (PERRY et al., 1976; POTTER et al., 1976; BERGER et al., 1981). $\mathrm{O}$ menor consumo de matéria seca nos animais que recebem ionóforos, sem alterar o ganho de peso, resulta em uma melhor eficiência alimentar. UTLEY et al. (1978), utilizando novilhas sob pastejo de azevém (16,0 a 20,58\% de PB), ofertando milho ad libitum, obtiveram ganhos semelhantes aos deste trabalho, sendo que e a inclusão de monensina também não influenciou no GMD; no entanto, o consumo de concentrado por dia foi menor no tratamento com ionóforo $(4,59$ vs $6,08 \mathrm{~kg})$, verificando-se uma melhor eficiência no uso da forragem e do suplemento.

\section{CONCLUSÃO}

Em termos de ganho de peso médio diário, não há vantagem em elevar o nível de suplementação de 0,5 para $1,0 \%$ do peso vivo, para novilhos na fase de terminação, quando a forragem ofertada é de alta qualidade e com um resíduo adequado. Nestas condições, ocorre apenas um efeito substitutivo do suplemento e a adição de lasalocida sódica ao mesmo não afeta o ganho de peso dos animais.

\section{REFERÊNCIAS BIBLIOGRÁFICAS}

BERGER, L.L., RICKE, S.C., FAHEY, G.C. Comparison of two forms and two levels of lasalocid with monensin on feedlot cattle performance. Journal of Animal Science, Champaign, v. 53 , n. 6, p. $1440-1445,1981$.

DAVIES, P., DILLON, A., MÉNDEZ, D. G. Efecto de la suplementacion energetica sobre el ambiente ruminal y la digestion de la fibra de un verdeo de avena. Revista Argentina de Producción Animal, v. 17, sup. 1, p.7, 1997.

EIFERT, E.C., OLIVEIRA, A.N., COSTA, E.C. et al. Desempenho de novilhos de sobreano em pastejo horário suplementados ou não, em pastagem de inverno. In.: VII DIA DE CAMPO "PRODUÇÃO DE BOVINOS DE CORTE, Santa Maria, 1997. Santa Maria: Universidade Federal de Santa Maria, Centro de Ciências Rurais, Departamento de Zootecnia, 1997. 
LUPATINI, G.C., RESTLE, J., CERETTA, M. et al. Avaliação da mistura de aveia preta (Avena strigosa) e azevém (Lolium multiflorum) sob pastejo submetida a níveis de nitrogênio. I Produção e qualidade de forragem. Pesquisa Agropecuária Brasileira, Brasília, v. 33, n. 11, p. 1939-1943, 1997.

MATTOS, D., SCAGLIA, G., PITALUGA, O. Uso de subprodutos agroindustriais para la suplementacion en ganaderia extensiva. In.: SIMPOSIO INTERNACIONAL DE UTILIZAÇÃO DE SUBPRODUCTOS AGROINDUSTRIAIS E RESÍDUOS DE COLHEITA NA ALIMENTAÇÃO DE RUMINANTES, 1992: São Carlos. Anais... São Carlos, 1992. p.245-259

MIERES, J.M. Suplementacion estratégica de la cria y recria ovina y vacuna. Tacuarembó, Uruguai: INIA, 1997. Relaciones planta animal suplemento.

MORENO, J.A. Clima do Rio Grande do Sul. Porto Alegre: Secretaria da Agricultura. 1961. 41p.

MORAES, A. de Produtividade animal e dinâmica de uma pastagem de pangola (Digitaria decumbens), azevém (Lolium multiflorum) e trevo branco (Trifolium repens) submetida a diferentes pressões de pastejo. Porto Alegre RS. 200 p. Tese (Doutorado em Zootecnia) - Faculdade de Agronomia da Universidade Federal do Rio Grande do Sul, 1991.

NRC - NATIONAL RESEARCH COUNCIL. Nutrient requirement of beef cattles. 7 ed. Washington: National Academy, 1996. 242p.

OLIVER, W.M. Effect of rumensin on gain of steers grazed on Costal berrmudagrass. Journal of Animal Science. V. 40, p. 190 (Abstr.), 1975.

PASCOAL, L.L. e RESTLE, J. Técnicas avançadas na recria e engorda de bovinos de corte. Santa Maria: UFSM, 1996. Suplementação a campo: p. 22-34.

PERRY, T.W., COOLEY, C.O., RICHARDSON, L.F. et al Effect of monensin on beef cattle performance. Journal of Animal Science, Champaign, v. 43, n. 3, p. 665-669, 1976.

POTTER, E.L., COOLEY, C.O., RICHARDSON, L.F. $\boldsymbol{e}$ t al. Effect of monensin on performance of cattle feed forage. Journal of Animal Science, Champaign, v. 43, n. 3, p. 665$669,1976$.
RESTLE, J., FERREIRA, M.V.B., PASCOAL, L.L. et al. Ganho de peso de novilhos suplementados em pastagem nativa melhorada no período de verão. In.: REUNIÃO ANUAL DA SOCIEDADE BRASILEIRA de ZOOTECNIA, 33, 1996, Fortaleza. Anais.... Viçosa: Sociedade Brasileira de Zootecnia, 1996. p. $436-437$.

RESTLE, J., ROSO, C., SOARES, A.B. Lasalocida sódica suplementada via sal para fêmeas de corte mantidas em pastagem. In: REUNIÃO ANUAL DA SOCIEDADE BRASILEIRA DE ZOOTECNIA, 34, 1997, Juiz de Fora. Anais... Viçosa: Sociedade Brasileira de Zootecnia, 1997. p. 179-181.

RESTlE, J., LUPATINI, G.C., ROSO, C. et al. Eficiência e desempenho de diferentes categorias de bovinos de corte em pastagem cultivada. Revista Brasileira de Zootecnia., Viçosa, v. 27, n. 2, p. 397-404, 1998.

RESTle, J., LUPATINI, G.C., VALENTE, A.V. $\boldsymbol{e}$ t $\boldsymbol{a}$. Avaliação da mistura de aveia preta (Avena strigosa) e azevém (Loliium multiflorum) sob pastejo submetida a níveis de nitrogênio. I - Produção animal. In.: REUNIÃO ANUAL DA SOCIEDADE BRASILEIRA DE ZOOTECNIA, 30, 1993, Rio de Janeiro. Anais... Viçosa: Sociedade Brasileira de Zootecnia, 1993. p. 283.

RISSO, D., AHUNCHAIN, M., ZARZA, A. Anim. en areas de ganaderia intensiva. In.: POSTY, P. Série técnica $n^{0} \mathbf{1 5}$. Uruguay: INIA, 1991. p. 51-65.

SAS, Institute Inc. SAS Language reference. Version 6. Cary, NC: SAS Institute, $1990.1042 \mathrm{p}$.

THONNEY, E., HEIDE, K., DUHAIME, D.J. Growth, feed efficiency and metabolite concentration of cattle feed high forage diets with lasalocid or monensin supplements. Journal of animal Science, Champaign, v. 52, n. 2, p. 427-433, 1981.

THOMAS, E.E. Pontos críticos da utilização de ionóforos em sistemas de cria. In.: II SIMPÓSIO INTERNACIONAL SOBRE PRODUÇÃO INTENSIVA DE GADO DE CORTE, São Paulo, 1998. Anais... p. 32-35.

UTLEY, P.R., NEVILLE Jr, W.E., MCCORMICK, W.C. Monensin fortified corn supplements in combination with testerine-estradiol implants and vaginal devices for finishing heifers on pasture. Journal of Animal Science, Champaign,v. 47 , n. 6, p. 1239-1242. 1978.

Ciência Rural, v. 29, n. 3, 1999. 